\title{
Optimization of Base Catalysts for Biodiesel Production from Jatropha Curcas Oil
}

\author{
Poojitha Reddy, Keerthana Reddy, Hanusha Durisety, Madhuri Pydimalla
}

\begin{abstract}
Rapid Industrialization has led to a drastic decline in fossil fuels giving rise to the need for environment-friendly biodiesel to fulfill the industrial appetite. Biodiesel from Jatropha curcas has significant potential for being an alternative fuel. The type of catalyst used for the production of biodiesel determines its fuel properties and is considered as a factor affecting its yield. The main objective of the current research work was to compare biodiesel properties obtained from the homogeneous and heterogeneous base catalyst. The properties were compared with ASTM standardized fuel properties to validate its potential as a replacement for diesel. In this study, the base-catalyzed transesterification process was used as a method to produce biodiesel from Jatropha curcas oil. $\mathrm{KOH}$ and $\mathrm{CaO}$ were used as homogenous and heterogeneous base catalysts. The biodiesel thus obtained is subjected to various characterization techniques such as acid number, fire point, flash point, cloud point, pour point, and also were checked for fluid characteristics like density and specific gravity. The results obtained (Example: Fire point: 126, Specific gravity: 0.87$)$ using $\mathrm{KOH}$ catalyst were promising as the values were in line with ASTM standard. Therefore, the major outcome of this research work is that a systematic comparison between two different catalysts has been carried out and it has been observed that $\mathrm{KOH}$ is an optimum catalyst that is economical and can be scaled up to produce maximum yield. This process can be considered as a zero-waste process as the by-product (glycerin) can further be considered as a raw material to produce commercial-grade products like bioplastics and soap. The important future prospects of this research work is that., as novel methods are taking centre stage to produce biodiesel through environmentally and economically acceptable processes., the jatropha-based biodiesel using effective base catalyst (KOH) through transesterification process will be taking a centre stage as it is found to be much safer fuel than diesel because of its higher flash point and fire point, decreases the dependence on imported petroleum and increases indigenous energy sufficiency.
\end{abstract}

Keywords: Biodiesel, Jatropha curcas oil, $\mathrm{KOH}$ and $\mathrm{CaO}$ catalysts, Transesterification.

Revised Manuscript Received on May 15, 2020.

* Correspondence Author

Poojitha Reddy, Chemical Engineering, Chaitanya Bharathi Institute of Technology, Hyderabad, India.

Keerthana Reddy, Chemical Engineering, Chaitanya Bharathi Institute of Technology, Hyderabad, India.

Hanusha Durisety, Chemical Engineering, Chaitanya Bharathi Institute of Technology, Hyderabad, India.

Dr. Madhuri Pydimalla*, Chemical Engineering Department, Chaitanya Bharathi Institute of Technology, Hyderabad, India. Email: pmadhuri_chem@cbit.ac.in/pmadhuri262@gmail.com

(c) The Authors. Published by Blue Eyes Intelligence Engineering and Sciences Publication (BEIESP). This is an open access article under the CC BY-NC-ND license (http://creativecommons.org/licenses/by-nc-nd/4.0/)

\section{INTRODUCTION}

$\mathrm{P}$ resently, the scientific community has focused its interest on issues related to the environment, sustainability, and energy [1]. The energy demand worldwide is expected to grow by $1.6 \%$ per year from now through the next decade [2]. Fossil fuel resources are therefore representing $88 \%$ of total world energy consumption. With fossil fuels being on the verge of exhaustion with increased demand, there is a need for finding alternative energy sources. In response to the need to develop sustainable energy resources and to address climatic change, the interest and development of biofuels have grown exponentially over the last few years.

The fuel comprising of mono-alkyl esters of long fatty acids derived from vegetable oils or animal fats is defined as biofuels [3]. It is renewable, biodegradable, non-toxic, and environmentally friendly. It can be used in compression-ignition (diesel) engines with little or no modification due to its adjustable physical and chemical properties. The major difference between biofuels and fossil fuel is in their carbon content and the amount of emission they produce due to combustion [4]. Biofuels produce much less carbon monoxide, sulphur dioxide, and unburned hydrocarbons compared to petroleum-based diesel fuels [5].

Currently, the focus has been the production of biodiesel using non-edible oils., as edible oils are more expensive than conventional petroleum-based fuels. Some of the popular non-edible oils being considered for biodiesel production, due to their ready availability and lower free fatty acid (FFA) content than edible oils include jatropha or seemaikattamankku (Jatropha curcas) [6], neem (Azadirachta indica) [7], tobacco seed (Nicotiana tabacum L.) [8], silk cotton (Ceiba pentandra) [9], jojoba (Simmondsia Chinensis) [10], cotton (Gossypium herbaceum) [11], coconut (Cocos nucifera) [12], soybean (Glycine max) [13], palm (Elaeis guineensis) [14], canola (Brassica napus) [15] and rubber seeds (H. brasiliensis) [16] etc.

Jatropha obtained from Jatropha curcas plant seeds, is very important in the production of biodiesel since it is a non-edible plant and will not cause competition on human food. Jatropha curcas is majorly grown in Andhra Pradesh, Chhattisgarh, Karnataka, Tamil Nadu, Rajasthan states in India. Some of the important properties of the plant include its hardness, rapid growth, easy propagation, and wide-ranging usefulness. The jatropha oil is a slow-drying oil which is odorless and colorless.

Blue Eyes Intelligence Engineering

\& Sciences Publication

(C) Copyright: All rights reserved.

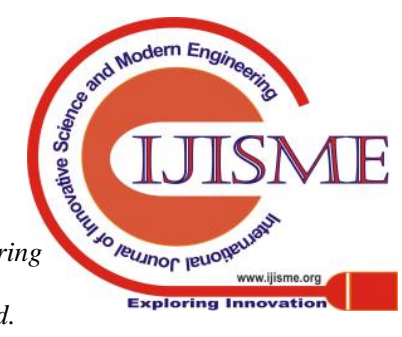


The oil content of jatropha seed ranges from 30 to $50 \%$ by weight and the kernel itself ranges from 45 to $60 \%$. The fatty acid composition of jatropha classifies it as a linoleic or oleic acid type, which is unsaturated fatty acids. The fatty acid composition of jatropha oil consists of palmitic, stearic, arachidic, oleic, and linoleic acids. The properties of this oil are envisaged as suitable as fuel oil. Biodiesel is made through a chemical process called transesterification process that involves altering the chemical properties of vegetable oil by using methanol [17]. Transesterification of vegetable oil is relatively a simple process that yields high conversion with glycerin as the only byproduct [18]. In transesterification, vegetable oil (triglycerides) is made to react with primary alcohol in the presence of a catalyst to produce biodiesel (fatty acid alkyl esters). Either biological or chemical catalysts are employed to activate the transesterification process. Enzymatic transesterification has an environmental advantage over the other methods but its major disadvantage is its prohibitive cost and its kinetic study is also difficult as many parameters are required to be taken into consideration [19]. The chemical catalyst for the transesterification process comprises of homogeneous agents (alkali or acid) and heterogeneous agents (solid acid or solid alkali catalysts). Depending on the type of catalyst used, the physical properties and yield of biodiesel are subject to variation.

Presently in India, the major gap between the production and the use of petroleum fuels is met by imports from other countries. Therefore, it is necessary to go in for alternative, renewable, and eco-friendly fuels. In this respect, the government of India has identified jatropha as a possible and promising alternative to diesel. Therefore, the main objective of this research work is to produce Biodiesel from Jatropha curcas oil using base (KOH and $\mathrm{CaO}$ catalysts) catalyzed transesterification process, test its properties, and compare its properties to ASTM standardized fuel properties to validate its potential application as a replacement for diesel. The major future scope of the current experimental study is to promote the use of jatropha (oil content varies from $35-40 \%$ of the seed mass) based biodiesel produced using effective base catalyst $(\mathrm{KOH})$ through transesterification process, as a partial substitute to diesel fuel as it exhibits excellent lubricity, higher density and cetane number in comparision with commercial petro-diesel. And also, the byproducts obtained during the production of biodiesel are useful for making glycerine and biofertilizer.

\section{MATERIALS AND METHODS}

\section{A. Materials}

Materials and apparatus used in the production of the biodiesel are as follows: Separating funnel, thermometer, magnetic stirrer, retort stand, water bath, hydrometer, pipette, measuring cylinder, oven, conical flask, digital weighing balance, stopwatch, hot plate, distilled water, methanol, Isopropyl alcohol, Potassium hydroxide pellets, Calcium oxide solution and Jatropha oil. The Jatropha curcas oil (purity: 98.5\%) used in this study was supplied by Sinhal Herbs, Industrial Estate, Neemuch, Madhya Pradesh, India.

\section{B. Methods}

Two steps are involved in the production of the biodiesel i.e.

(1) Pretreatment of Jatropha oil (for water removal):

$100 \mathrm{ml}$ of fresh J.oil was added to a $250 \mathrm{ml}$ flask and the weight was recorded as $\left(\mathrm{W}_{1}\right)$. The oil was then heated to $100^{\circ} \mathrm{C}$. For every 15 mins, the weight of the flask consisting of oil was recorded. This process was done for about 2 hours and weight was recorded as $\left(\mathrm{W}_{2}\right)$. Therefore, the final weight of the oil was $\mathrm{W}_{1}-\mathrm{W}_{2}$.

\section{(2) Base-catalyzed transesterification process:}
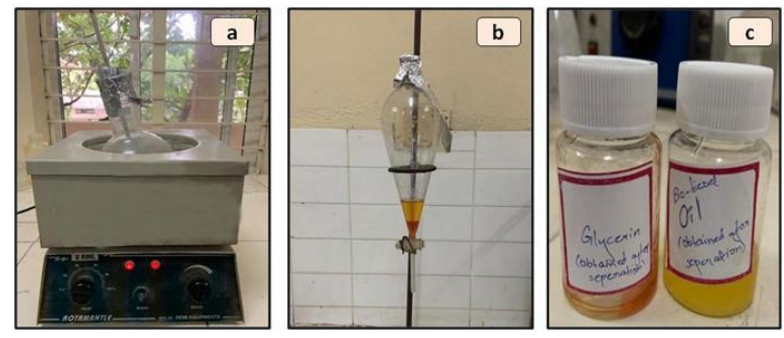

Fig. 1. (a). Heating of Jatropha oil along with the mixture (KOH pellets and methanol) in an adiabatic heater, (b). Separation of biodiesel (upper layer) and glycerin (lower layer) in separating funnel, (c). The obtained biodiesel and glycerin solutions.
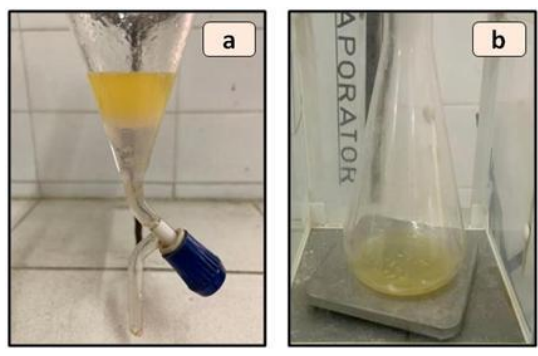

Fig. 2. (a). Washing biodiesel with water for removal of catalyst, (b). Biodiesel after removal of the catalyst.

i. $10 \mathrm{ml}$ of methanol was taken in a round bottom flask with the help of pipette and $\mathrm{KOH}$ pellets of appr. 0.5 gram was added. The solution was properly stirred until the potassium hydroxide pellet was completely dissolved.

ii. Jatropha oil of appr. $25 \mathrm{ml}$ was poured into the solution and the flask was placed in an adiabatic heater to bring its temperature to $60^{\circ} \mathrm{C}$ (Fig. 1a).

iii. The mixture was stirred vigorously for 2 hours using a magnetic stirrer.

iv. The mixture was then allowed to settle for 24 hours in a separating funnel.

$\mathrm{v}$. The biodiesel (top layer) was then poured into a separate beaker, while the lower layer (which comprises of glycerin) was collected from the bottom of the separating funnel (Fig. 1b).

vi. The quantity of biodiesel collected was measured and recorded (Fig. 1c).

Published By: Blue Eyes Intelligence Engineering \& Sciences Publication (C) Copyright: All rights reserved. 
vii. The weighed biodiesel is heated on a water bath for 30 mins to evaporate the excess methanol.

viii. For removing the catalyst appr. $5 \mathrm{ml}$ of biodiesel was taken in a separating funnel, to which $10 \mathrm{ml}$ of water was added and thoroughly shaken to dissolve the catalyst (Fig. 2).

ix. The mixture was then allowed to settle for 5 mins in a separating funnel.

$\mathrm{x}$. The upper and lower layers represent biodiesel and water.

xi. Water is removed carefully by opening the valve of the separating funnel.

xii. This process is repeated twice and biodiesel was again measured and recorded.

xiii. A decrease in the weight of the biodiesel was observed which indicates the removal of methanol and catalyst.

\section{(3) Soap making from glycerin:}

Transesterification is a process in which the properties of the oil are chemically altered. This process was preferred because of its simplicity and it produces fewer by-products. Glycerin was the only by-product obtained in this process. The obtained glycerin was used for the production of soap. The glycerin obtained as a by-product during the transesterification process was collected and weighed (Fig. 3a). This was transferred into a $250 \mathrm{ml}$ conical flask. The conical flask was heated either by a double boiling method or in an oven or on a hot plate. When it was heated on a hot plate, aluminum foil was wrapped around the base of the flask to avoid breaking of glycerin molecules by direct heating (Fig. 3b). The conical flask was heated until the entire glycerin is melted. 8-10 drops of essential oil like lavender oil was added for scent and mixed properly. The contents of the conical flask were transferred into $200 \mathrm{ml}$ beaker or soap molds. The beaker or soap mold was coated beforehand by oil like coconut oil so that glycerin does not stick to the walls of the container. After the glycerin was poured into a beaker, isopropyl alcohol was sprayed on the glycerin. This was to remove the air bubbles from the glycerin and helps to form soap of continuous solid phase. The contents of the beaker were placed in a freezer and allowed to freeze overnight. After freezing, the beaker was removed and soap formed was taken out. If the soap is stuck in the beaker, the beaker is placed in warm water for 5 min which melts the glycerin sticking to the walls of the beaker

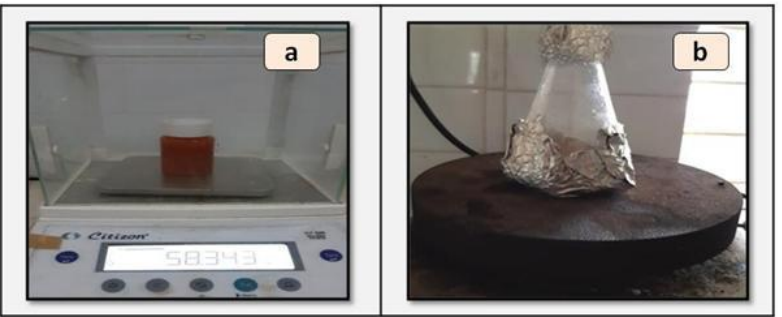

Fig. 3. (a). Weighing the collected glycerin from the transesterification process, (b). Heating glycerin solution on a hot plate.

\section{Characterization of Biodiesel}

ASTM standards were used for the characterization of biodiesel.

\section{i. Conversion test (27/3 test):}

For $3 \mathrm{ml}$ of biodiesel taken, $27 \mathrm{ml}$ of methanol was added and vigorously shaken in a separating funnel. The mixture was left to settle for 5 mins. If the mixture forms a clear colorless liquid (i.e. methanol is completely dissolved in biodiesel) it can be confirmed that the obtained product is biodiesel. If the mixture forms a white cloudy layer and separates into two layers, then it confirms that the obtained product is not biodiesel. So, the $27 / 3$ test is a go/no-go test with a visual indication [20].

\section{ii. Determination of Acid value (ASTM D664):}

The acid value is defined as the number of milligrams of $\mathrm{KOH}$ that is required to neutralize the free fatty acids in one gram of fat. Since fatty acids are weakly acidic, $\mathrm{NaOH}$ or $\mathrm{KOH}$ are required to titrate the acidic content. The standard solution of $\mathrm{KOH}$ was prepared by dissolving $0.56 \mathrm{gm}$ in 100 $\mathrm{ml}$ conical flask containing $100 \mathrm{ml}$ of water. The mixture was thoroughly shaken for a uniform concentration of $0.1 \mathrm{~N}$. The contents were transferred into a clean burette. $100 \mathrm{ml}$ of isopropyl alcohol was added to $20 \mathrm{gm}$ of jatropha oil in a clean conical flask. It was placed on a water bath for 5 min to dissolve oil in alcohol. 10 drops of phenolphthalein were added to the flask and titrated against $0.1 \mathrm{~N} \mathrm{KOH}$ taken in the burette till light pink color endpoint is obtained.

\section{iii. Determination of Fire point and Flash point (ASTM D93):}

Biodiesel was introduced in the container, and its temperature is slowly increased. A thermometer was immersed in the biodiesel to measure its temperature. An ignition source was held above the surface of the biodiesel. As the surface molecules vaporize, at a certain temperature the vapor mix catches fire, and the surface of biodiesel starts burning. This temperature was noted as the fire point temperature.

\section{iv. Determination of Cloud point (ASTM D7467):}

Biodiesel was taken in an airtight bottle and kept in a freezer. For every $5 \mathrm{~min}$, the temperature of the biodiesel was measured using a thermometer. The temperature at which the biodiesel transforms into a thick solid and wax formation is observed., was considered as the cloud point.

\section{v. Determination of Pour point (ASTM D5949):}

Biodiesel was taken in a jar and kept in a freezer. For every $5 \mathrm{~min}$, the temperature is measured with a thermometer. When biodiesel was completely frozen, it is bought out of the freezer. Now, the temperature of biodiesel is allowed to increase by leaving it to the atmosphere. For every 2 minutes, the jar is tilted horizontally to check if the biodiesel is flowing. The temperature at which biodiesel starts flowing is considered as pour point. 


\section{vi. Determination of Specific gravity (ASTM D1298):}

To determine the specific gravity of the biodiesel a $50 \mathrm{ml}$ flask is used. The empty flask weight is labeled as $\mathrm{W}_{1} \mathrm{gm}$. The flask was then filled with $50 \mathrm{ml}$ biodiesel, weighed, and labeled as $\mathrm{W}_{2}$ gm. The flask is emptied, washed, and filled with water. The weight of the flask containing water is noted as $W_{3}$ gm. The specific gravity of the biodiesel is calculated as follows: The weight of Biodiesel $=\mathrm{W}_{2}-\mathrm{W}_{1}$ gm

The weight of Water $=\mathrm{W}_{3}-\mathrm{W}_{1}$ gm

Sp.Gr $=($ Weight of biodiesel $/$ Weight of water $)=\left(W_{2}-W_{1}\right) /$ $\left(\mathrm{W}_{3}-\mathrm{W}_{1}\right)$

\section{vii. Determination of Moisture content (ASTM D1796):}

The oil sample was weighed and the mass is taken as $\left(\mathrm{W}_{1}\right)$ was dried in the oven and the weight after drying was taken as $\left(\mathrm{W}_{2}\right)$. The percentage of moisture in the oil was calculated using the following equation:

$\%$ Moisture content $=\left(\mathrm{W}_{1}-\mathrm{W}_{2} / \mathrm{W}_{1}\right) \times 100$

Where $W_{1}$ is the weight of the oil sample before drying (grams) and $\mathrm{W}_{1}$ is the weight of the oil sample after drying (grams).

\section{RESULTS AND DISCUSSIONS}

The results of this research work will be discussed under the following groups:

\section{i. Production and yield of biodiesel:}

The biodiesel yielded from the chemical reaction was carried out under standard conditions. The equipment and materials were kept clean and samples were maintained at optimum temperature. In order to prevent emulsification, the required mol of the catalysts $(\mathrm{KOH}$ and $\mathrm{CaO})$ was used. The reactant mixture was stirred vigorously so that the highest yield of biodiesel (possible under the given condition) was produced. The biodiesel thus produced was free from glycerin because warm water was used to wash the biodiesel. The yield was calculated using the following equation:

Yield of biodiesel $=$ (weight of biodiesel/weight of biodiesel + weight of glycerin)

The yield of biodiesel was almost 50\% using $\mathrm{KOH}$ as a catalyst and was observed to be increasing with an increase in the amount of jatropha oil (Fig. 4a). Whereas, the yield was $35 \%$ using $\mathrm{CaO}$ as a catalyst (Fig 4b). The slight variation in the attained yields could be since $\mathrm{KOH}$ is a bronsted base and mixes thoroughly with methanol. Whereas in the case of $\mathrm{CaO}$ catalyst, it has to be protected from ambient $\mathrm{CO}_{2}$ and $\mathrm{H}_{2} \mathrm{O}$ because it deteriorates the catalytic basic sites. Lesser yield (for $\mathrm{CaO}$ catalyst) can also be contributed to the decomposition of $\mathrm{CaCO}_{3}$.

For the transesterification process, catalytically basic sites allow methanol to be transformed into nucleophile that attacks carbonyl carbon in a molecule of glycerides. Therefore, it seemed that the strong basic sites required for catalyzing the vegetable oil transesterification thus producing lesser yield.

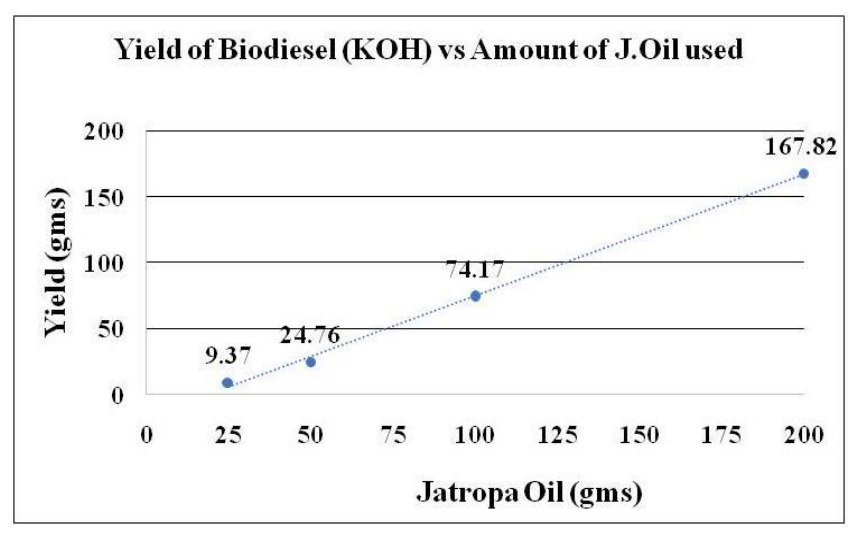

Fig. 4. (a). Yield of biodiesel using $\mathrm{KOH}$ as a catalyst

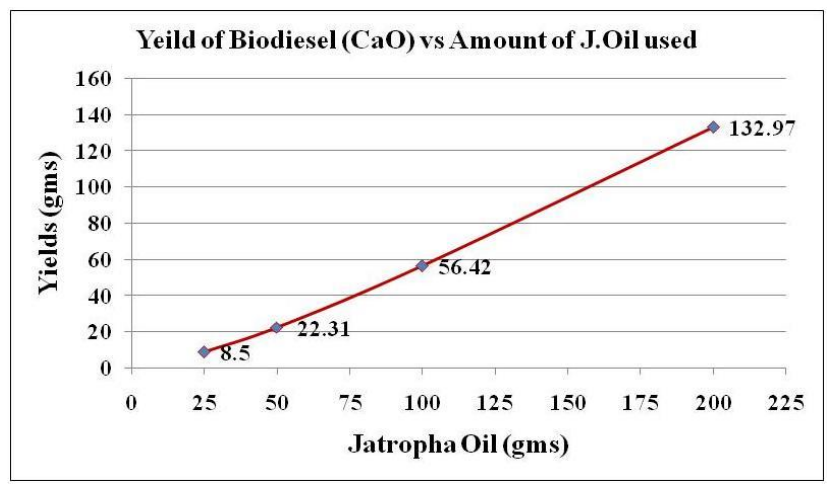

Fig. 4. (b). Yield of biodiesel using $\mathrm{CaO}$ as a catalyst.

ii. Analysis of the result from the characterization of biodiesel produced:

The characterization results of the biodiesel produced are presented in Table 1 . The results were placed with the corresponding limit set for (ASTM D 6751 and ASTM D 975) biodiesel standard.

Table- I: Properties of Biodiesel produced from Jatropha oil using $\mathrm{KOH}$ and $\mathrm{CaO}$ catalysts

\begin{tabular}{|c|c|c|c|c|c|}
\hline S.No & Property & $\begin{array}{c}\text { J.BD* } \\
\text { with } \\
\text { KOH } \\
\text { catalyst }\end{array}$ & $\begin{array}{c}\text { J.BD* } \\
\text { with CaO } \\
\text { catalyst }\end{array}$ & $\begin{array}{c}\text { ASTM D } \\
6751 \text { for } \\
\text { BD }^{*}\end{array}$ & $\begin{array}{c}\text { ASTM D } \\
975 \text { for } \\
\text { BD }^{*}\end{array}$ \\
\hline 1 & $\begin{array}{l}\text { Specific } \\
\text { gravity }\end{array}$ & 0.87 & 0.75 & 0.88 & 0.85 \\
\hline 2 & $\begin{array}{c}\text { Acid no. } \\
\mathrm{mg} / \mathrm{KOH} / \mathrm{g}\end{array}$ & 0.35 & 1.73 & 0.5 & NS \\
\hline 3 & $\begin{array}{l}\text { Density at } \\
24^{\circ} \mathrm{C} g / \mathrm{L}\end{array}$ & 0.896 & 0.872 & $\begin{array}{c}0.86 \text { to } \\
0.90\end{array}$ & 0.85 \\
\hline 4 & $\begin{array}{l}\text { Moisture } \\
\text { content }\end{array}$ & trace & trace & $\begin{array}{c}0.05 \% \\
\max \end{array}$ & $\begin{array}{c}0.05 \% \\
\max \end{array}$ \\
\hline 5 & $\begin{array}{c}\text { Flash point } \\
\left({ }^{\circ} \mathrm{C}\right)\end{array}$ & 103 & 163 & $100-170$ & $60-80$ \\
\hline 6 & $\begin{array}{c}\text { Fire point } \\
\left({ }^{\circ} \mathrm{C}\right)\end{array}$ & 126 & 179 & NS* & NS* \\
\hline 7 & $\begin{array}{l}\text { Pour point } \\
\left({ }^{\circ} \mathrm{C}\right)\end{array}$ & -2 & -1 & -15 to 10 & -35 to -15 \\
\hline 8 & $\begin{array}{c}\text { Cloud point } \\
\left({ }^{\circ} \mathrm{C}\right)\end{array}$ & 2 & 4 & Report* & Report* \\
\hline
\end{tabular}


J.BD*: Jatropha. Biodiesel, BD*: Biodiesel, NS*: Not specified by ASTM Report*: According to the specifications cloud point has to be reported to the buyers.

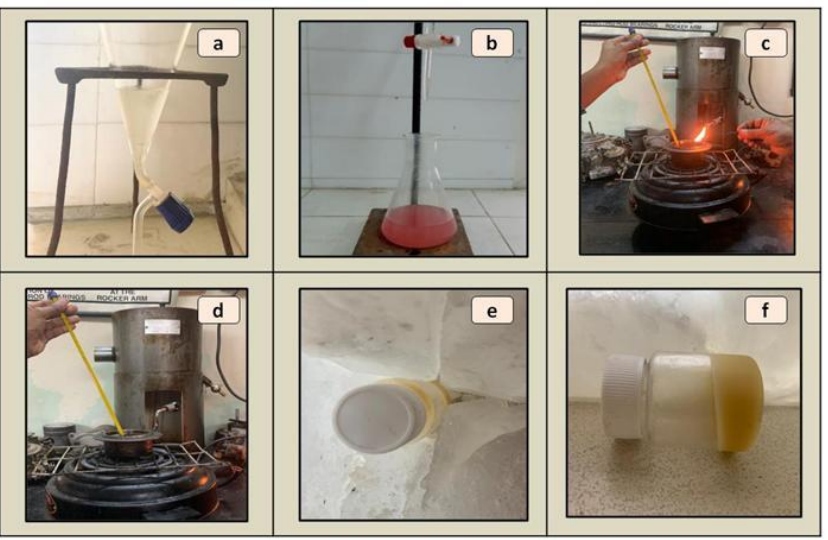

Fig. 5 . Biodiesel during - (a). Methanol testing method 27/3-passed, (b). Acid value, (c). Fire point, (d). Flash point, (e). Cloud point, (f). Pour point.

Methanol test (Fig. 5a) concluded that the product formed was biodiesel as no precipitate formation was observed. This holds true for both the catalysts $(\mathrm{KOH}$ and $\mathrm{CaO})$.

The acid value determines the amount of free fatty acids in a fat (Fig. 5b). If high concentrations of free fatty acids exist, these free fatty acids will alter the oil quality, the required purification stages, and the stability of the resulting biodiesel [20]. Since oils that have more than $1 \%$ free fatty acid content or an acid value of $3 \mathrm{mg} \mathrm{KOH} / 1 \mathrm{~g}$ of oil, have a significantly lower conversion to fatty acid methyl esters using only alkaline catalyzed transesterification [20]. The acid value of biodiesel produced using the $\mathrm{KOH}$ catalyst was 0.35 and 1.73 using the $\mathrm{CaO}$ catalyst. Both have shown a deviation from the specified standard range. It was a little higher than that of petrol-diesel (0.35), but it does not harm the engine parts [22].

Fire point and Flash point are generally defined for liquids (Fig. 5c \& d). As the temperature of the liquid increases, the surface molecules are vaporized and mixed with the surrounding air. The fire point is the lowest temperature at which this air-vapor mixture above liquid catches fire when a distant ignition source or fire is introduced. The fire point is independent of the temperature of the ignition source. Below the fire point, the fuel cannot burn when the ignition source is removed from its vicinity. Flash point is defined as the lowest temperature at which oil can vaporize to form an ignitable mixture. Biodiesel has a higher flash point in the range of $100-170^{\circ} \mathrm{C}$ as compared to that of the Petro-diesel (flash point of $50^{\circ} \mathrm{C}$ ). This ensures that the biodiesel sample is safe for use. Fuels with lower flash points tend to ignite at lower temperature making it highly dangerous. The flash point of jatropha oil decreases after transesterification, which shows that its volatile characteristics had improved and it is also safe to handle. The fire points of biodiesel produced using $\mathrm{KOH}$ and $\mathrm{CaO}$ are $126^{\circ} \mathrm{C}$ and $179^{\circ} \mathrm{C}$ respectively and the flash point is $103^{\circ} \mathrm{C}$ and $163^{\circ} \mathrm{C}$ respectively for $\mathrm{KOH}$ and $\mathrm{CaO}$ catalysts. The flash point for biodiesel is higher compared to Petro-diesel as fire and flash points are dependent on the alcohol content in them. Since there is a very trace amount of alcohol content in bio feeds the fire flash point increased drastically.

Cloud point is one of the main physical properties of liquid fuel. It is the temperature at which the liquid forms cloudy appearance (Fig. 5e) and wax crystals start to form when the temperature of the fuel is decreased. Cloud point indicates that beyond this temperature, wax in fuel starts forming and fuel viscosity increases. This does not allow the fuel to flow properly in the pipes and clogs the pipelines. The lower the cloud point temperature, the better is the fuel. The cloud point temperatures obtained for biodiesel produced from the $\mathrm{KOH}$ catalyst and $\mathrm{CaO}$ catalyst were found to be $2^{\circ} \mathrm{C}$ and $4^{\circ} \mathrm{C}$ respectively. Both were within the ASTM standards range. ASTM D975 was modified in 2008 to allow up to $5 \%$ biodiesel to be blended into the fuel.

Pour point is the temperature at which the fuel continues to flow. Decreasing the temperature of fuel beyond pour point, the fuel stops flowing i.e. it loses its flow characteristics and starts to freeze (Fig. 5f). Pour point is opposite to that of the cloud point, it is the lowest temperature at which the fuel can be pumped freely. Cloud point and pour point are the performance indicators under cold weather conditions. The pour point for biodiesel produced from the $\mathrm{CaO}$ catalyst was found to be $-1^{\circ} \mathrm{C}$. Whereas, the pour point for biodiesel produced from the $\mathrm{KOH}$ catalyst was found to be $-2^{\circ} \mathrm{C}$. Both were within the specified ASTM range. The cloud point and pour point of the biodiesel produced are higher than that of the petrol diesel. As a result of this higher value, the performance of biodiesel in cold conditions will be worse than that of petroleum diesel [23].

The density of a fuel is another important factor for good performance; the higher the density, the more difficult it becomes to pump the fuel. The density of biodiesel produced from $\mathrm{KOH}$ and $\mathrm{CaO}$ catalysts was found to be $0.896 \mathrm{~g} / \mathrm{L}$ and $0.872 \mathrm{~g} / \mathrm{L}$ which were on par with the standards. ASTM Standard D941 test method was used to measure the density of the biodiesel. The specific gravity of the biodiesel produced is 0.895; this is well within the range of the standard. Higher density implies more mass of fuel per unit volume for vegetables compared to diesel oil. The higher mass of fuel would give higher energy available for work output per unit volume.

As high moisture content in biofuel leads to an increase in consumption value and a decrease in combustion value, it is recommended to consider biofuel with low or negligible moisture content. Moisture content determines how fuel gets combusted. If the moisture content is too low the fuel burns too rapidly and if the moisture content is too high then the fuel does not burn completely. Normally, it inhibits the transesterification reaction and, together with free fatty acids, leads to parallel reactions of saponification with the consequent formation of soaps [24]. Moreover, excess water reduces oil and biodiesel oxidation stability. According to ASTM standards, the moisture content of biodiesel should be less than $0.05 \%$. The biodiesel obtained from the $\mathrm{KOH}$ catalyst and $\mathrm{CaO}$ catalyst contained moisture in traces and satisfied ASTM standards for biodiesel. 
Therefore, from the above observations and attained results it can be stated that., biodiesel produced using the $\mathrm{KOH}$ catalyst has properties well in range with the ASTM standards and also produced better yield when compared to biodiesel produced from $\mathrm{CaO}$ catalyst. This can be attributed to the fact that $\mathrm{KOH}$ is a bronsted base and offers a better catalytic site. Whereas, when $\mathrm{CaO}$ catalyst is used the yield decreased due to side formation of $\mathrm{CaCO}_{3}$.

\section{iii. Soap making from glycerin:}

Since the globalization of the world, the chemical industries expanded widely with an increase in the number the by-products produced, some of which are harmful to the environment are still released into the atmosphere. In such a scenario, the process with zero waste or zero-emission technology is necessary to be explored, discovered, and implemented. Since the by-product obtained from the current process (transesterification), was used for soap manufacture (Fig. 6)., the process can be referred to as a zero-waste process. With the potential for all the products to being completely used, it adds much more value to this process of producing biodiesel from Jatropha oil when compared to that production of conventional petroleum diesel.

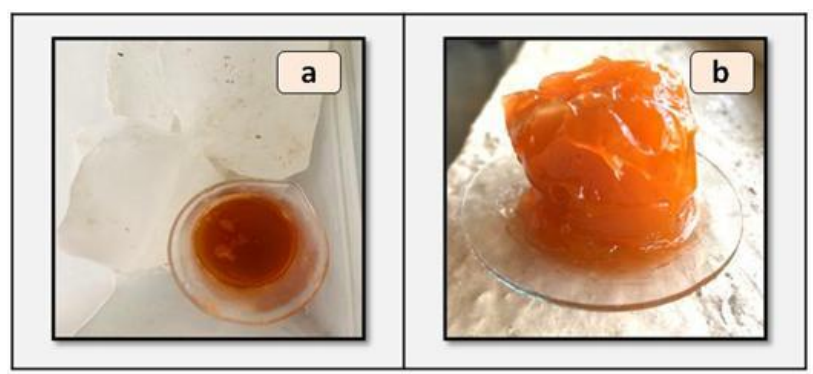

Fig. 6. (a). Glycerin placed in the freezer after spraying Isopropyl alcohol, (b). Final soap formation from glycerin.

\section{CONCLUSIONS}

1. The current research work has confirmed that jatropha oil may be used as feed material to obtain biodiesel.

2. Experimental results show that base-catalyzed transesterification is a promising area of research for the production of biodiesel on a large scale.

3 . The test results have shown that the obtained jatropha based biodiesel from base catalysts has their properties (Flash point: $100-170$; Cloud point: $2^{\circ} \mathrm{C}-4^{\circ} \mathrm{C}$; Pour point: $-1^{\circ} \mathrm{C}$ to $-2^{\circ} \mathrm{C}$ ) well within the specified ASTM range.

4. A systematic comparison between two different catalysts has been carried out. From the characterization results, the physical properties of biodiesel produced from jatropha oil using the $\mathrm{KOH}$ catalyst were found to be within the ASTM specified limits.

5. Biodiesel characteristics like specific gravity and density are close to that of petrol and diesel.

6. Separation of biodiesel and glycerol layers and removal of the residual catalyst was easier in the case of the $\mathrm{CaO}$ catalyst.

7. The methodology used can be said to be a zero-waste process as glycerin which is the by-product of the chemical reaction can be sold to the pharmaceutical companies since it is used to produce commercial-grade products such as creams, soaps, toothpaste, and bioplastics.

\section{ACKNOWLEDGMENT}

The authors thank CBIT management for extending their support and providing us with numerous facilities to carry on with the experimental work. Sincere thanks to technicians Mr. Shipley and Mr. Sanjeev Reddy (Chemical Engg Dept, CBIT Hyderabad) for assisting in handling various equipment.

\section{REFERENCES}

1. Luque, J H Clark, Biodiesel-like biofuels from simultaneous transesterification/esterification of waste oils with a biomass-derived solid acid catalyst, ChemCatChem, vol. 3, 2011, pp. 594-597.

2. Baskar Thangaraj, Pravin Raj Solomon, Bagavathi Muniyandi, Srinivasan Ranganathan, Lin Lin, Catalysis in biodiesel production-a review, Clean Energy, vol. 3, 2018, pp. 1-22.

3. Borges Markus, Díaz Luisa, Recent developments on heterogeneous catalysts for biodiesel production by oil esterification and transesterification reactions: a review, Renewable and Sustainable Energy Reviews, vol. 16, 2012, pp. 2839-2849.

4. W. Marshall, L. G. Schumacher, S. A. Howell, Engine exhaust emissions evaluation of a cummins L10E when fueled with a biodiese blend, SAE Technical Paper No. 952363, 1995, doi:10.4271/952363

5. Xie Wenlei, Li Haitao, Alumina-supported potassium iodide as heterogeneous catalyst for biodiesel production from soybean oil, Journal of Molecular Catalysis A-chemical, vol. 255, 2006, pp. 1-9.

6. Pramanik Krishna, Properties and use of Jatropha curcas oil and diesel fuel blends in compression ignition engine, Renewable Energy, vol. 28, 2003, pp. 239-248.

7. Thangaraj Baskar, Ramachandran Kasturi, Raj Samuel, Homogeneous catalytic transesterification of renewable Azadirachta indica (Neem) oi and its derivatives to biodiesel fuel via acid/alkaline esterification processes, International Journal of Renewable Energy \& Biofuels, vol. 11, 2014, pp. 1-12, DOI: 10.5171/2014.515961

8. Veljković Vlada, Lakićević S.H, Stamenković Olivera, Lazic Miodrag, Biodiesel production from tobacco (Nicotiana tabacum L.) seed oil with a high content of free fatty acids, Fuel, vol. 85, 2006, pp. 2671-2675.

9. Norjannah B, Ong H.C, Masjuki H. H, Effects of methanol and enzyme pretreatment to Ceiba pentandra biodiesel production, Energy Sources, Part A: Recovery, Utilization, and Environmental Effects, vol. 39, 2017, pp. 1-8.

10. Sandouqa A, Al-Hamamre Z, Energy analysis of biodiesel production from jojoba seed oil, Renewable Energy, vol. 130, 2019, pp. 831-842.

11. Mahdavi V, Monajemi A, Optimization of operational conditions for biodiesel production from cottonseed oil on $\mathrm{CaO}-\mathrm{MgO} / \mathrm{Al} 2 \mathrm{O} 3$ solid base catalysts, Journal of the Taiwan Institute of Chemical Engineers, vol. 45, 2014, pp. 2286-2292.

12. Endut A, Abdullah S. H. Y. S, Hanapi N. H. M, Hamid S. H. A, Lananan $\mathrm{F}$, et al., Optimization of biodiesel production by solid acid catalyst derived from coconut shell via response surface methodology, International Biodeterioration \& Biodegradation, vol. 124, 2017, pp. 250-257.

13. Saydut Abdurrahman, Kafadar A.B, Aydin Firat, Erdogan S, Kaya C, et al., Effect of homogeneous alkaline catalyst type on biodiesel production from soybean [Glycine max (L.) Merrill] oil, Indian Journal of Biotechnology, vol. 15, 2016, pp. 596-600.

14. Nongbe M. C, Ekou T, Ekou L, Yao K. B, Le Grognec E, et al., Biodiesel production from palm oil using sulfonated graphene catalyst, Renewable Energy, vol. 106, 2017, pp. 135-141.

15. Dizge Nadir, Keskinler Bulent, Enzymatic production of biodiesel from canola oil using immobilized lipase, Biomass and Bioenergy, vol. 32, 2008, pp. 1274-1278.

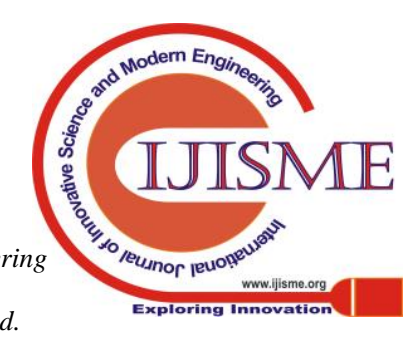


16. Arvind Narayan Sundaram, Shobana Sutha, Characteristics and thermal efficiency of biofuels: rubber seed oil as a renewable energy source, International Journal of Science and Modern Engineering, vol. 1, 2013, pp. 18-20.

17. Silveira, D. Foster, Availability of Biomass Across the Globe, 2008, http://www.forestencyclopedia.net/.

18. Juan Joon Ching, Kartika Damayani, Wu Ta, Taufiq-Yap, Yun Hin, Biodiesel production from jatropha oil by catalytic and non-catalytic approaches: An overview, Bioresource Technology, vol. 102, 2011, pp. 452-60.

19. Kalantari Mohammad, Arpanaei Ayyoob, Evaluation of biodiese production using lipase immobilized on magnetic silica nanocomposite particles of various structures, Biochemical Engineering Journal, vol. 79, 2013, pp. 267-273.

20. Alok Kumar Tiwari, Akhilesh Kumar, Hifjur Raheman, Biodiesel production from jatropha oil (Jatropha curcas) with high free fatty acids: An optimized process, Biomass and Bioenergy, vol. 31, 2007, pp. 569-575.

21. Dias J. M, Alvim-Ferraz M. C. M, Almeida M. F, Comparison of the performance of different homogeneous alkali catalysts during transesterification of waste and virgin oils and evaluation of biodiesel quality, Fuel, vol. 87, 2008, pp. 3572-3578.

22. Singh Raghubansh Kumar, Padhi Saroj, Characterization of jatropha oil for the preparation of biodiesel, Natural Product Radiance, vol. 8, 2009, pp.127-132.

23. C. Peterson, D. Reece, Emissions characteristics of ethyl and methyl estero frappe seed oil compared with low sulfur diesel control fuel in a chassis dynamometer test of a pickup truck, Transactions of the American Society of Agricultural Engineers, vol. 39, 1996, pp. 805-816.

24. Hindryawati Noor, Maniam Gaanty Pragas, Karim Md. Rezaul, Chong Kwok Feng, Transesterification of used cooking oil over alkali metal ( $\mathrm{Li}, \mathrm{Na}, \mathrm{K}$ ) supported rice husk silica as potential solid base catalyst, Engineering Science and Technology, an International Journal, vol. 17, 2014, pp. 95-103.

\section{AUTHORS PROFILE}

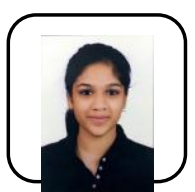

Poojitha Reddy Giri, is a fourth-year student of Chaitanya Bharathi Institute of Technology, Hyd, currently pursuing her bachelor's degree in chemical engineering. She has always been keen on understanding complex science behind everyday things. Her curiosity about such has aided in her journey to explore Chemical Engineering and its broad applications. She has interned at the reputed Dr. Reddy's and has assisted in of their on-going projects with enthusiasm. Her area of research interest includes Environmental Sustainability, Biochemical Engineering and Green Technology

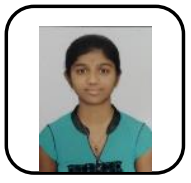

Keerthana Reddy Chittireddy, is a fourth year student of Chaithanya Bharathi Institute of Technology studying her bachelor's in chemical engineering. She has done her internship in IICT-Hyderabad on Online Monitoring of Fluid Catalytic Cracking Unit for three months and also another intern at Kesoram Birla Cements-Karimnagar on the manufacturing process of cement. She has participated in national conferences held at NIT-Calicut and Osmania University. Her interest lies in analyzing and searching novel methods in different areas that include Green technology, Heat transfer, Biofuels and also Petroleum Engineering.

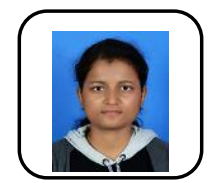

Hanusha Durisety, is B.Tech. Chemical Engineering, Third year student at Chaitanya Bharathi Institute of Technology, Hyderabad. She has done her internship at Aurobindo Pharmacompany, Hyderabad in May 2019. She is a student member of IIChE. She has attended various conferences organized by IIChE Institutions and has taken part in inter college competitions. She has presented her research work in various seminars. Her area of research interest is in Engineering Materials, Biofuels, Sustainable energy and Heat Transfer.

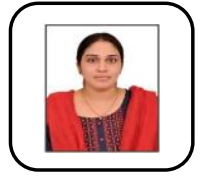

Dr. Madhuri Pydimalla, received her Bachelor's degree from Osmania University and Master's degree from JNTUH in the field of Chemical Engineering. She was awarded $\mathrm{PhD}$ in the research area of "Pulp and Paper Technology" from BITS PILANI in Sep 2019. She has total 12 yrs of teaching experience in academic field working as Assistant Professor in Chaitanya Bharathi Institute of Technology, Hyderabad and concurrent 6 years of research experience at BITS PILANI- Hyderabad Campus. She has published 06 research papers in reputed International SCI \& Scopus indexed journals and presented her research work in 10 Conferences (05 international and 05 National). Her area of research includes Pulp \& Paper, Reaction Kinetics, Seperation processes, Surface coatings, Biofuels. 